The University of Maine

\title{
DigitalCommons@UMaine
}

Electronic Theses and Dissertations

Fogler Library

$12-2003$

\section{Structural and Kinetic Characterization of Myoglobins from Eurythermal and Stenothermal Fish Species}

Peter William Madden

Follow this and additional works at: http://digitalcommons.library.umaine.edu/etd

Part of the Biochemistry Commons

\section{Recommended Citation}

Madden, Peter William, "Structural and Kinetic Characterization of Myoglobins from Eurythermal and Stenothermal Fish Species" (2003). Electronic Theses and Dissertations. 302.

http://digitalcommons.library.umaine.edu/etd/302

This Open-Access Thesis is brought to you for free and open access by DigitalCommons@UMaine. It has been accepted for inclusion in Electronic Theses and Dissertations by an authorized administrator of DigitalCommons@UMaine. 


\title{
STRUCTURAL AND KINETIC CHARACTERIZATION OF \\ MYOGLOBINS FROM EURYTHERMAL AND \\ STENOTHERMAL FISH SPECIES
}

\author{
By \\ Peter William Madden \\ B.S. University of Maine, 2001

\begin{abstract}
A THESIS
Submitted in Partial Fulfillment of the

Requirements for the Degree of

Master of Science

(in Biochemistry)
\end{abstract}

The Graduate School

The University of Maine

December, 2003

Advisory Committee:

Robert E. Cashon, Assistant Professor of Biochemistry

Michael E. Vayda, Professor of Biochemistry

Dorothy E. Croall, Professor of Biochemistry 


\title{
STRUCTURAL AND KINETIC CHARACTERIZATION OF MYOGLOBINS FROM EURYTHERMAL AND \\ STENOTHERMAL FISH SPECIES
}

\author{
By Peter William Madden \\ Thesis Advisor: Dr. Robert E. Cashon \\ An Abstract of the Thesis Presented \\ in Partial Fulfillment of the Requirements for the \\ Degree of Master of Science \\ (in Biochemistry) \\ December, 2003
}

Teleost myoglobin $(\mathrm{Mb})$ proteins from four fish species inhabiting different temperature environments were used to investigate the relationship between protein function and thermal stability. Mb was isolated from yellowfin tuna (homeothermal warm), mackerel (eurythermal warm), and the Antarctic teleost Notothenia coriiceps (stenothermal cold). Zebrafish (stenothermal tropical) myoglobin was expressed from cloned cDNA. $N$. coriiceps $\mathrm{Mb}$ cDNA has also been cloned, expressed at $20^{\circ} \mathrm{C}$, and isolated from E. coli, but was not used in any of the functional and kinetic studies. These proteins differed in oxygen affinity, as measured by $\mathrm{O}_{2}$ dissociation rates and $\mathrm{P}_{50}$ values, and thermal stability as measured by autooxidation rates. Mackerel Mb had the highest $\mathrm{P}_{50}$ value at $25^{\circ} \mathrm{C}(3.7 \mathrm{~mm} \mathrm{Hg})$, corresponding to the lowest $\mathrm{O}_{2}$ affinity, followed by zebrafish $(1.0 \mathrm{~mm} \mathrm{Hg})$, yellowfin tuna $(1.0 \mathrm{~mm} \mathrm{Hg})$, and $N$. coriiceps $(0.6 \mathrm{~mm} \mathrm{Hg})$. Oxygen dissociation rates and Arrhenius plots were similar between all teleost species in this study, with the exception of mackerel myoglobin, which was two fold faster at all 
temperatures tested. Myoglobin from the Antarctic teleost had the highest autooxidation rate $\left(0.44 \mathrm{~h}^{-1}\right)$, followed by mackerel $\left(0.26 \mathrm{~h}^{-1}\right)$, zebrafish $\left(0.22 \mathrm{~h}^{-1}\right)$, and yellowfin tuna $\left(0.088 \mathrm{~h}^{-1}\right)$. Primary structural analysis revealed residue differences distributed throughout the polypeptide sequences, making it difficult to identify, which, if any, residues contribute to structural flexibility. However, analysis of molecular dynamics trajectories indicates that $\mathrm{Mb}$ from the eurythermal mackerel is the most flexible protein within the D loop and FG turn, which correlates with the $\mathrm{O}_{2}$ affinity and kinetic data. 


\section{ACKNOWLEDGEMENTS}

I would like to give a special thanks to my thesis advisor, Dr. Robert Cashon, for

all your guidance and support during my undergraduate and graduate studies. Your hard work and dedication to this project has been so instrumental to my success, and it has been such a great pleasure being your advisee. Things just won't be the same without hearing that good old Texas Twang. I want to thank Dr. Michael Vayda for allowing me to work in your lab and also for all your extensive guidance and support the past two years. Somehow you've always been able to make time for all your students, even during your busy schedule. I also won't forget the great team we make on the golf course! I thank Dr. Dorothy Croall for always being there for me, whether its scientific or everyday advice, your support has been so important to my accomplishments in this program. You coined the name "LMP" and for some strange reason I think that will always continue to follow me.

I also want to thank all the graduate students and faculty of the BMMB department. Without all of you there is no way the BMMB graduate programs would be such a great success. A big thanks to everyone in the Vayda lab who I've been with the past 2 years, especially Mike Babcock for all your hard work on this project and for putting up with all of my many questions.

Finally, a very special thanks to friends, family, and especially my parents, without your support none of this could have been possible. 


\section{TABLE OF CONTENTS}

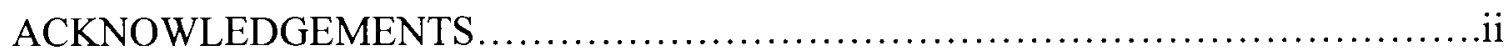

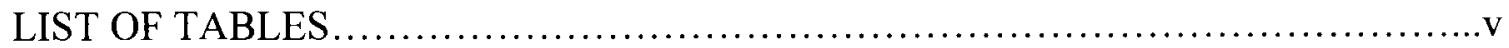

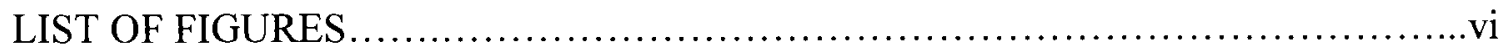

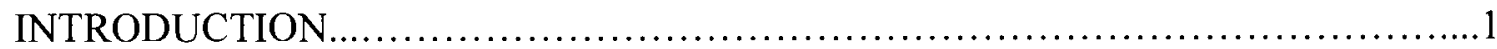

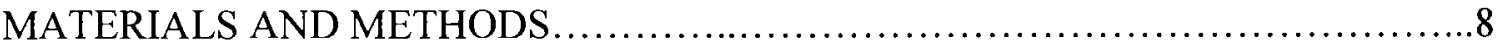

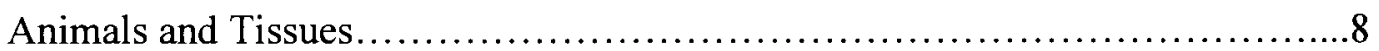

Reverse Transcription and RACE.....................................8

Mb Pimer Design.....................................................

PCR Amplification.................................................

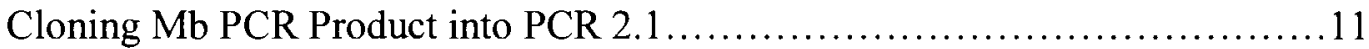

Expression of Zebrafish and $N$. coriiceps Myoglobin......................11

Mb Purification...........................................................

Oxygen Dissociation.....................................................

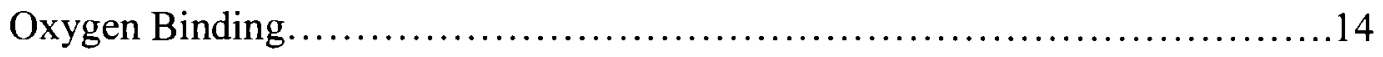

Autooxidation Measurements..............................................14

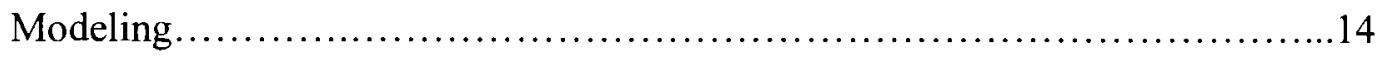

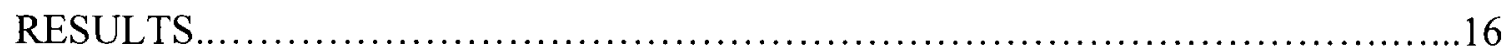

Kinetic and Functional Characterization of Teleost Myoglobin Protein...........16

Structural Modeling of Myoglobin Proteins................................22

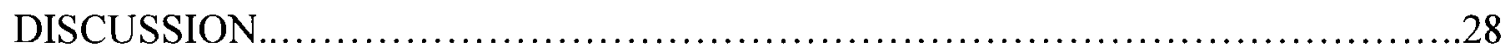




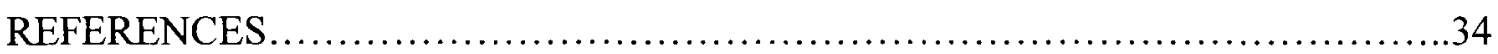

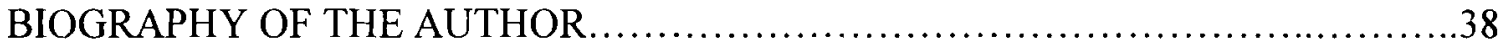




\section{LIST OF TABLES}

Table 1. Species boy temperatures and tolerance classification......................6

Table 2. Zebrafish and $N$. coriiceps myoglobin primers......................... 10

Table 3. Mb oxygen equilibrium and autooxidation............................. 18 


\section{LIST OF FIGURES}

Figure 1. Oxygen dissociation rate constants............................... 17

Figure 2. Arrhenius plots of oxygen dissociation rate constants..................20

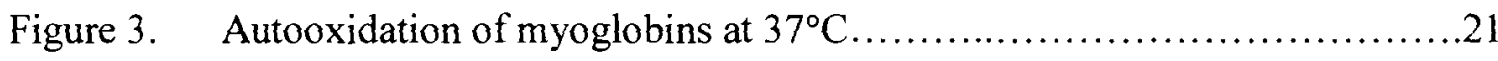

Figure 4. Primary sequence alignment of teleost fish myoglobin....................23

Figure 5. RMS deviations of the positions of backbone $\mathrm{C} \alpha$ carbons during the molecular dynamics simulations................................24

Figure 6. Ribbon structure of sperm whale myoglobin.........................26

Figure 7. Ribbon structure of yellowfin tuna myoglobin........................27 


\section{INTRODUCTION}

Myoglobin (Mb) is a small, single subunit intracellular oxygen binding protein found in aerobic muscle and heart ventricle of mammals, reptiles, amphibians, teleosts and chondrichthid fish. This protein facilitates diffusion of oxygen to the mitochondria of aerobic muscle, and may also store oxygen for metabolic respiration during periods of hypoxia or high oxygen demand (Wittenberg and Wittenberg, 1989). Not surprisingly, the richest sources of myoglobin are found in the muscles of aquatic diving mammals, such as seals and whales, which must store oxygen for relatively long periods. The amount of myoglobin varies widely between different species with the myoglobin content of teleost red muscle and cardiac tissue generally falling on the low side. For example, levels of myoglobin in cardiac tissue vary from high concentrations such as $2780 \mathrm{mg} / 100$ $\mathrm{g}$ tissue in ringed seal (O'Brien et al, 1992) to undetectable levels in some species including some teleost fishes (Vayda et al., 1997, Sidell et al., 1997). Further, mice lacking myoglobin that survive gestation, suffer no acute effects of the loss exhibiting increased vascularization to compensate for the lack of myoglobin (Garry et al., 1998). While it is clear that the oxygen-binding/diffusion function of myoglobin isn't absolutely critical under all conditions, the importance of myoglobin to physiological function is witnessed by the presence of compensating changes in physiology, muscle anatomy, life style, etc. which have often evolved in its absence.

Deoxymyoglobin and oxymyoglobin are the two most common derivatives of this heme protein. Deoxymyoglobin is the ferrous $\left(\mathrm{Fe}^{2+}\right)$ myoglobin derivative, which experiences the loss of one valence electron, and is primarily found under low $\mathrm{pO}_{2}$ concentrations. Since deoxymyoglobin lacks a $6^{\text {th }}$ position ligand it is easily bound by 
high field ligands such as oxygen, carbon monoxide, and nitric oxide. Carbon monoxide also binds coordinately to heme iron atoms in a manner similar to that of oxygen, but the binding of carbon monoxide to heme is much stronger than that of oxygen. This preferential binding of carbon monoxide to heme iron is largely responsible for the asphyxiation that results from carbon monoxide poisoning. The ferrous form of myoglobin can be oxidized by one electron to ferric myoglobin (metmyoglobin, $\mathrm{Fe}^{3+}$ ). Oxymyoglobin is the other primary derivative, which in its ferrous form, can also be oxidized to metmyoglobin unless a reducing agent is present. This oxidation of oxymyoglobin to metmyoglobin is also referred to as autooxidation. Autooxidation of myoglobin is favorable under three main conditions: at oxygen tensions where half of the total ferrous myoglobin is in the deoxy form; if $\mathrm{Cu}^{2+}$ or $\mathrm{Fe}^{3+}$ atoms are present; and if the physiological pH is decreased (Livingston and Brown, 1981).

It is also important to note that the $\mathrm{P}_{50}$, the oxygen pressure at which myoglobin is $50 \%$ saturated, is between that of hemoglobin and cytochrome oxidase. This allows for myoglobin to take up $\mathrm{O}_{2}$ that has been dumped by hemoglobin in the capillaries and transport this $\mathrm{O}_{2}$ to the muscle cells for subsequent storage and release to cytochrome oxidase, which has a higher affinity for $\mathrm{O}_{2}$ (Voet et al., 2002).

The length of the mammalian myoglobin peptide is 154 amino acids; 153 after cleavage of the N-terminal methionine. By contrast, teleost myoglobin genes encode a 147 amino acid myoglobin that is processed to a mature 146 amino acid polypeptide after removal of the $\mathrm{N}$-terminal methionine. Despite differences in primary amino acid sequences, myoglobins from all species are predicted to fold into the same tertiary structure referred to as the "globin fold" (Perutz et al., 1965, Watts et al., 1980). The 
monomeric mammalian myoglobin molecule is built up from eight $\alpha$-helices that form a box for the heme group, an iron atom surrounded by a porphyrin ring. Helices $\mathrm{E}$ and $\mathrm{F}$ build the walls of the box for the heme; $\mathrm{B}, \mathrm{G}$ and $\mathrm{H}$ helices are the floor; and helices $\mathrm{C}$ and D are on the opposite side. X-ray crystallography (Takano, 1977; Phillips, 1980) and protein dynamic studies (Lambright et al., 1994) of mammalian myoglobin indicate that the protein lacks a discrete channel for oxygen binding and release. Instead, oxygen movement to and from the heme pocket is dependent on flexing of the myoglobin structure. The X-ray crystal structure of yellowfin tuna myoglobin (Birnbaum et al., 1994) indicates that the D-helix, in mammalian $\mathrm{Mb}$, is absent and is replaced by a random coil "loop" (Fig. 6 and 7). Oxygen dissociation data also revealed that oxygen dissociates three times faster from yellowfin tuna than from sperm whale myoglobin. This structural change of the D-helix may be a major contributing factor to the kinetic differences observed between teleost and mammalian myoglobins.

In their general features, teleost myoglobins, exemplified by the known structure of tuna myglobin, clearly resemble other vertebrate myoglobins. The tuna protein maintains the characteristic tertiary "globin fold" found in other vertebrate myoglobins along with the conserved architecture and environment of active site found in mammalian and reptilian myoglobins (Lattman et al., 1971, Birnbaum et al., 1994, Nardini et al., 1995). This strict conservation of the architecture and environment of the heme pocket is reflected functionally in the general absence of differences in the thermodynamic oxygen association constants seen in a wide variety of species (Antonini and Brunori, 1971). Teleost and mammalian Mb each have sets of distinctive conserved residues but the two groups also share a set of conserved residues, particularly residues involved in the 
oxygen-binding pocket and interactions with the heme group. Due to the homologies that do exist, a good deal can be inferred about the details of teleost myoglobin function by analogy to the very well studied mammalian proteins, in particular sperm whale myoglobin.

Mammalian $\mathrm{Mb}$ is one of the most well characterized proteins for structurefunction studies. However, mammalian Mb does not serve as a good model for protein thermal acclimation studies, because mammals are homeothermic at $37^{\circ} \mathrm{C}$. By contrast, ectothermic fishes are ideal models to explore functional adaptation to temperature. However, few teleost myoglobins have been studied. Kinetic studies indicate that the oxygen dissociation rates of mammalian myoglobins slow as temperature decreases (Stevens and Carey, 1981; Cashon et al., 1997). In comparison of mammalian Mb with teleost $\mathrm{Mb}$, there appears to be a correlation between $\mathrm{Mb}-\mathrm{O}_{2}$ affinity and physiological temperature (Nichols and Weber, 1989). For instance, coho salmon Mb binds oxygen with lower affinity $\left(\mathrm{P}_{50}=1.78\right.$ torr) than sperm whale $\mathrm{Mb}\left(\mathrm{P}_{50}=0.44\right.$ torr $)$. Further, kinetic measurements of oxygen dissociation rates of myoglobin isolated from the Antarctic teleost Chionodraco rastrospinosus show that it releases oxygen 2.5 times more rapidly than mammalian myoglobin over a wide range of temperatures (Cashon et al., 1997). Similar results were reported by Marcinek et al., (2001) who have demonstrated that $\mathrm{Mb}$ oxygen affinity and binding kinetics from several endothermic and ectothermic fish correlate to their physiological temperatures.

Fields and Somero (1997) proposed that proteins are optimized to function at their physiological temperature. These authors examined the enzymatic activity of $\mathrm{A}_{4}$-lactate dehydrogenase (LDH) and citrate synthase (CS) among cold and warm-water fishes 
ranging in temperature from $0^{\circ} \mathrm{C}$ in polar climates to $25^{\circ} \mathrm{C}$ in tropical habitats. They concluded that the enzyme activities, at their physiological temperatures, show approximately a two-fold difference between Antarctic and tropical fish species. Temperature compensation appears to be the result of coevolution of flexibility in the protein to allow maximized velocity at cold temperature. Yet protein structures are optimized such that $\mathrm{K}_{\mathrm{m}}$ for substrates is the same at the respective functional (body) temperatures of various teleost fishes (Hochachka and Somero, 2002). Thus, teleost fish with differing habitats provide an excellent system in which to compare the natural variation of $\mathrm{Mb}$ function.

We therefore examined the primary and modeled structure, functional characteristics, and kinetics of myoglobin proteins from stenothermic fish that inhabit a very narrow temperature range (polar and tropical), homeothermic fish that maintain an elevated core body temperature, and eurythermic fish that experience a wide range of temperatures in their normal activities (Table 1). Yellowfin tuna was also chosen in this study to serve as the teleost reference control, since the crystal structure for this teleost myoglobin is known and resembles other vertebrate and mammalian myoglobins. We determined the oxygen dissociation rates, oxygen affinity, and autooxidation rates of Mbs from yellowfin tuna, zebrafish, $N$. coriiceps, and mackerel. Our results suggest that $\mathrm{Mb}$ functional kinetics do not correlate with physiological temperature regimes. Mb oxygen dissociation rates from the Antarctic species, $N$. coriiceps, were comparable to those of mammalian and teleost myoglobins with higher body temperatures. However, stability studies (autooxidation) were not comparable in the fish inhabiting vastly different temperature regimes. This autooxidation data illustrated a clear dependence of functional 
$\begin{array}{lll}\text { S. scombrus (Mackerel) } \quad 12 \text { to } 25^{\circ} \mathrm{C} & \text { Eurythermic }\end{array}$

T. albacares (Yellowfin Tuna) $30^{\circ} \mathrm{C} \quad$ Homeothermic

$\begin{array}{lll}N \text { coriiceps } & (-) 1.86 \text { to } 1.0^{\circ} \mathrm{C} & \text { Stenothermic cold }\end{array}$

$\begin{array}{lll}\text { D. rerio (Zebrafish) } 26 \text { to } 28^{\circ} \mathrm{C} & \text { Stenothermic warm }\end{array}$

Table 1. Fish species body temperatures and tolerance classification. 
stability on environmental temperature of the organism (Cashon et al. 1997). Structural comparisons were done employing molecular mechanics simulations and root mean square (RMS) profiles of protein backbone flexibility and primary amino acid alignments were also used to examine which regions of the protein might be contributing to increased flexibility. 


\section{MATERIALS AND METHODS}

\section{Animals and Tissues}

Zebrafish were a gift from the University of Maine Zebrafish Facility. Fish hearts were removed and immediately frozen in liquid nitrogen for long-term storage at $-80^{\circ} \mathrm{C}$. Two hundred zebrafish hearts were used for attempts at isolation Mb protein. Yellowfin tuna, Notothenia coriiceps, and mackerel myoglobin proteins were purified from heart ventricle tissue as describe previously (Cashon et al. 1997). For mRNA isolation, one hundred zebrafish hearts were pulverized to a fine powder in liquid $\mathrm{N}_{2}$, using a mortar and pestle. Powder was homogenized in Trizol reagent $(50-100 \mathrm{mg} / \mathrm{ml})$ (Gibco BRL/Life Technology) according to the manufacturer protocol and all RNA was stored in $\mathrm{dH}_{2} \mathrm{O}$ at $-80^{\circ} \mathrm{C}$ prior to use.

\section{Reverse Transcription and Rapid Amplification of cDNA Ends (RACE)}

First strand cDNA was synthesized from 50-500 ng template mRNA using 200 units Superscript II reverse transcriptase (Gibco BRL/Life Technology), primed by 0.5 $\mu \mathrm{M}$ oligo $\mathrm{dT}_{30}$ primer (Gibco BRL/Life Technology) in a $20 \mathrm{ul}$ reaction volume. Each reaction included $50 \mathrm{mM}$ Tris- $\mathrm{HCl}(\mathrm{pH} 8.5), 3 \mathrm{mM} \mathrm{MgCl}$, $75 \mathrm{mM} \mathrm{KCl}, 0.01 \mathrm{M}$ DTT, and $5 \mathrm{mM}$ of each dNTP. Synthesis was carried out by incubation at $42^{\circ} \mathrm{C}$ for $50 \mathrm{~min}$. Reactions were terminated by incubation at $70^{\circ} \mathrm{C}$ for $15 \mathrm{~min}$. Double stranded cDNA was synthesized by incubation at $16^{\circ} \mathrm{C}$ for $1.5 \mathrm{~h}$ using a $10 \mu \mathrm{l}$ aliquot of the first strand cDNA synthesis reaction. Each $80 \mu \mathrm{l}$ reaction included the following: $100 \mathrm{mM} \mathrm{KCl}, 10$ $\mathrm{mM} \mathrm{NH}_{4} \mathrm{SO}_{4}, 5 \mathrm{mM} \mathrm{MgCl} 2,150 \mu \mathrm{M} \beta-\mathrm{NAD}, 20 \mathrm{mM}$ Tris (pH 7.5), $5 \mathrm{mg} / \mathrm{ml} \mathrm{BSA}, 5$ 
$\mathrm{mM}$ of each dNTP, 2.4 units $E$. coli DNA polymerase (Sigma), 4.8 units $E$. coli DNA ligase (New England Biolabs), and 1.0 unit E. coli RNase H (Promega). Completion of double stranded cDNA synthesis was accomplished by the addition of 0.5 units $T_{4}$ DNA polymerase (Promega) and incubation at $16^{\circ} \mathrm{C}$ for $1.0 \mathrm{~h}$, followed by addition of EDTA/glycogen to terminate the reaction. Double stranded cDNA was purified by phenol: chloroform: isoamyl alcohol (25:24:1) extraction and resuspended in $10 \mu \mathrm{l} \mathrm{H}_{2} \mathrm{O}$ according the Marathon cDNA amplification protocol (Clonetech). Marathon cDNA adapter $(10 \mu \mathrm{M})\left(\right.$ Clonetech) ligation to $5 \mu \mathrm{l}$ ds cDNA was facilitated by $\mathrm{T}_{4}$ DNA ligase (Clonetech) in a $10 \mu \mathrm{l}$ reaction volume containing $50 \mathrm{mM}$ Tris- $\mathrm{HCl}(\mathrm{pH} 7.8), 10 \mathrm{mM}$ $\mathrm{MgCl}_{2}, 1 \mathrm{mM} \mathrm{DTT}, 1 \mathrm{mM} \mathrm{ATP}$, and 5\% (w/v) Polyethylene glycol (MW 8,000).

\section{Mb Primer Design}

$\mathrm{Mb}$ degenerate primers $(\mathrm{O}$ and $\mathrm{P})$ were designed using the COnsensusDEgenerate Hybrid Oligonucleotide Primer (CODEHOP) strategy (Rose, et al 1998; Henikoff et al 1999) and are listed in Table 2. Species-specific nested primers were designed using Primer Select in DNASTAR (Higgins et al., 1988). Zebrafish and $N$. coriiceps full-length primers containing Bam $\mathrm{HI}$ and Nde I restriction sites are also listed in Table 2.

\section{PCR Amplification}

Myoglobin sequences were determined from extensive overlap of DNA segments amplified from cDNA. PCR reactions were carried out according to the manufacturer's' protocol using RedTaq DNA polymerase (Sigma) including the following components: 


\begin{tabular}{ll}
\hline Primer Name & Nucleotide Sequence \\
\hline Myo O & 5'-d(CTG AAC TGC TGG GGC AAG RTN GAR SCN GA)-3' \\
Myo P & 5'-d(CCC CGG GAA GCC GAD YTC YTT RTA NT)-3' \\
ZfNdel & 5'-d(CAT ATG GCT GAT CAT GAT CTG)-3' \\
ZfBamHl & 5'-d(GGA TCC TCA TTA ACC GGC AAA TCC GAT)-3' \\
NcorNdel & 5'-d(CAT ATG GCT GAC TTT GAC ATG)-3' \\
NcorBamHl & 5'-d(GGA TCC TCA TTC AGT GAA GCC)-3'
\end{tabular}

Table 2. Zebrafish and $N$. coriiceps myoglobin primers. Myo $\mathrm{O}$ and Myo $\mathrm{P}$ are degenerate primers used for isolation of myoglobin cDNA from libraries. Zebrafish and $N$. coriiceps species specific primers were used for subsequent cloning into BamH1 and Ndel restriction sites of the pET9b vector (Novagen). (R) Adenosine or Guanine; (S) Guanine or Cytosine; (Y) Cytosine or Thymine; (N) any deoxynucleotide. 
$1 \mu \mathrm{M}$ primer (depicted on the PCR strategy schematic), $10 \mathrm{mM}$ each $\mathrm{dNTP}, 2.5 \mathrm{mM}$ $\mathrm{MgCl}_{2}, 50 \mathrm{mM}$ Tris- $\mathrm{HCl}(\mathrm{pH} 8.5), 5.0 \mathrm{uL}$ ds cDNA template. PCR products were separated by electrophoresis through $1.5 \%$ agarose gels in $1 \mathrm{X}$ Tris Borate EDTA (TBE) at 75 volts for 30 min and purified using QiaQuick Gel Purification Kit (Qiagen).

\section{Cloning Mb PCR Product into PCR 2.1}

PCR products corresponding to $444 \mathrm{bp}$ were purified using Qiagen gel extraction kits and ligated into pCR2.1 vectors according to manufacturer protocol (TA cloning kits, Invitrogen). INV $\alpha F^{\prime}$ competent cells were transformed according to the manufacturer's protocol (TA cloning kit, Invitrogen). Transformed cells were plated on 1.5\% LauriaBertani (LB) agarose $(50 \mu \mathrm{g} / \mathrm{ml}$ ampicillin) containing $40 \mu \mathrm{l} \mathrm{X}$-gal $(40 \mu \mathrm{g} / \mu \mathrm{l})$. Plates were incubated at $37^{\circ} \mathrm{C}$ overnight. Single white colonies were inoculated into $5 \mathrm{ml} \mathrm{LB}$ media (50 $\mu \mathrm{g} / \mathrm{ml}$ ampicillin) and incubated at $37^{\circ} \mathrm{C}$ overnight with shaking (225 rpm). Plasmids were isolated and purified from $5 \mathrm{ml}$ cell pellets using Qiagen plamid miniprep kits (Gibco). Purified pCR2.1/Mb plasmids were digested with Eco RI (NEB) at $37^{\circ} \mathrm{C}$ for $1 \mathrm{~h}$. Digestion products were separated by electrophoresis on $1.5 \%$ agarose gels in $1 \mathrm{X}$ TBE at 75 volts for $1 \mathrm{~h}$. Plasmids containing the $456 \mathrm{bp} \mathrm{Mb}$ insert were submitted to the DNA sequencing facility at the University of Maine.

\section{Expression of Zebrafish and $N$. coriiceps Myoglobin}

cDNAs encoding the zebrafish and $N$. coriiceps myoglobin sequence were sequenced and cloned into the pET-9b vector (Novagen), and expressed in the $E$. coli strain BL21 (DE3), without pLysS, (Novagen). Frozen stocks are kept at $-80^{\circ} \mathrm{C}$. A 
$100 \mathrm{~mL}$ overnight culture was grown at $37^{\circ} \mathrm{C}$ in $\mathrm{LB}$ media containing $30 \mu \mathrm{g} / \mathrm{mL}$ of kanamycin and shaken at $250 \mathrm{rpm}$. The overnight culture was split and added to two $1 \mathrm{~L}$ LB media $(30 \mu \mathrm{g} / \mathrm{ml} \mathrm{kan})$ and incubated at $37^{\circ} \mathrm{C}$ (Zebrafish) and $20^{\circ} \mathrm{C}(N$. coriiceps $)$ with shaking at $250 \mathrm{rpm}$ to an $\mathrm{OD}_{600}$ of approximately 1.5 . Induction was maintained under the control of the T7 promoter by adding isopropyl-beta-D-thiogalactopyranoside (IPTG) to make a $0.4 \mathrm{mM}$ final concentration. The culture remained shaking for approximately $2-3 \mathrm{~h}$ maintaining culture temperature and cells were harvested by centrifugation at $5000 \mathrm{rpm}$ for $10 \mathrm{~min}$ using the JLA 10.5 rotor. Reddish-brown cell pellets were washed and resuspended $2 \mathrm{X}$ using $25 \mathrm{ml} 150 \mathrm{mM} \mathrm{NaCl}$ and centrifuged at $5000 \mathrm{rpm}$ for $15 \mathrm{~min}$ using the JLA 25.5 rotor. Cell pellets were weighed and stored at $80^{\circ} \mathrm{C}$ overnight. Cell pellets were resuspended at room temperature with BugBuster reagent (Novagen), using $5 \mathrm{ml}$ reagent per gram of cells. The susupension was vortexed and incubated for 10 to $20 \mathrm{~min}$ on a shaking platform at room temperature, and the cell debris was removed by centrifugation at $16,000 \mathrm{x}$ g for $25 \mathrm{~min}$ using the JA 25.5 rotor. The viscous blood red supernatant was sonicated for $2 \mathrm{~min}$ in order to break up any remaining bacterial DNA, and stored at $-80^{\circ} \mathrm{C}$.

\section{Mb Purification}

Crude $\mathrm{Mb}$ extracts from tissue homogenization and expressed $E$. coli extracts were applied to a P-60 (Bio-Rad) gel filtration column $(2.5 \times 50 \mathrm{~cm})$ equilibrated in 150 $\mathrm{mM}$ Tris/ $1 \mathrm{mM}$ EDTA, $\mathrm{pH}$ 8.4. The appropriate fractions were pooled, concentrated under $40 \mathrm{psi}$ of air in a stirred PM-10 membrane cell filtration system (Amicon). This sample was applied to a DEAE Sepharose (Pharmacia) ion-exchange column $(2 \times 10 \mathrm{~cm})$ 
equilibrated in $150 \mathrm{mM}$ Tris/ $1 \mathrm{mM}$ EDTA, $\mathrm{pH}$ 8.4. Mb fractions were again pooled, concentrated, and stored at $-80^{\circ} \mathrm{C}$ until use.

\section{Oxygen Dissociation}

Prior to determination of oxygen dissociation rate constants, all myoglobin samples were reduced to the ferrous state using the enzymatic reduction system (Hegesh et al., 1967). The following components of the reduction system are listed as their final concentrations in solution: NADP $(45 \mu \mathrm{M})$, glucose-6-phosphate $(0.67 \mathrm{mM})$, glucose-6phosphate dehydrogenase $(3.3 \mu \mathrm{g} / \mathrm{ml})$, ferredoxin $(0.17 \mu \mathrm{M})$, ferredoxin-NADP reductase $(0.08 \mu \mathrm{M})$, catalase $(1.7 \mu \mathrm{g} / \mathrm{ml})$, and potassium phospate buffer, $\mathrm{pH} 7.0(0.1 \mathrm{M})$. Myoglobin solutions $(10 \mu \mathrm{M})$ were deoxygenated by rapidly mixing with a $2.0 \mathrm{mg} / \mathrm{ml}$ solution of sodium dithionite using a SX.18MV Stopped-Flow Reaction Analyser (Applied Photophysics). Deoxygenation kinetics were followed at $430 \mathrm{~nm}$. Rate constants were estimated by standard nonlinear squares fitting of the date to a first order mechanism. Each reported value represents the average of 3 individual determinations. Error bars were not used since all values were consistently less than $2 \%$ from each other. 


\section{Oxygen Binding}

Oxygen equilibrium constants were estimated by the tonometric method (Riggs et al., 1956) using $25 \mathrm{mM}$ phosphate buffer $(\mathrm{pH} 7.5)$ at $25^{\circ} \mathrm{C}$ and in the presence of the enzymatic reduction system (Hegesh et al., 1967) to maintain the heme iron in the ferrous form.

\section{Autooxidation Measurements}

The autooxidation rate constants of the myoglobins at $37^{\circ} \mathrm{C}$ were measured in 25 $\mathrm{mM}$ phosphate buffer $(\mathrm{pH} 7.5)$ containing $1 \mathrm{mM}$ EDTA. The buffer was pre-equilibrated in the water-jacketed cell holder of a Beckman DU7500 spectrophotometer. An aliquot of myoglobin, sufficient to make a $10 \mu \mathrm{M}$ final concentration, was injected into the $37^{\circ} \mathrm{C}$ buffer. The solution was quickly mixed with a Pasteur pipet prior to starting sample collection. Spectra from 350 to $700 \mathrm{~nm}$ were collected every 5 min for a total of 360 min. After collection, the spectral/time sequences were fitted to a first order mechanism using singular value decomposition (SVD) followed by nonlinear least squares procedures (Cashon and Alayash, 1995).

\section{Modeling}

Homology models of the myoglobins of mackerel, $N$. coriiceps, and zebrafish were constructed based on the amino acid sequences of these proteins and the published X-ray structure of yellowfin tuna myoglobin utilizing InsightII and Charmm (Brooks et al., 1983). Using InsightII, the appropriate amino acid substitutions were made to convert the amino acid sequence of the yellowfin tuna myoglobin into the primary 
sequence of the target myoglobin while holding the backbone conformation constant. This derived structure was then energy minimized to relieve strain in the newly substituted amino acid sidechains.

The target protein structure was next solvated in an octahedral volume using periodic boundaries constructed from an initial cube shape with an average edge-length of $73.67 \AA$, dependent on the specific myoglobin being modeled. An average of 5597 water molecules were contained in the octahedral simulation boxes, again varying slightly depending on the specific myoglobin. Initial minimization and temperature equilibration of structures was performed as described below.

Waters and protons on the protein structure were first minimized for 100 steps while constraining the remainder of the structure. Following this, 5 rounds of dynamics were run ( $20 \mathrm{ps}$ each) to equilibrate the structure and bring it to the proper temperature for the simulation. During the first of these initial dynamics runs, the protein backbone was harmonically constrained to allow equilibration of sidechains and solvation waters. Production dynamics consisted of five 40 ps time windows with an integration time of 0.002 ps. Coordinates of the trajectory were saved every 2 ps. The root mean square (RMS) positions of the alpha backbone carbons were calculated from these combined trajectories and used to estimate flexibility of the protein backbone structure. 


\section{RESULTS}

\section{Kinetic and Functional Characterization of Teleost Mb Protein}

Myoglobin was isolated from mackerel, $N$. coriiceps, and yellowfin tuna as described previously (Cashon et al., 1997). An unsuccessful attempt was made to purify Mb from 200 Danio rerio (zebrafish) hearts, but due to the limited amounts of tissue available, insufficient $\mathrm{Mb}$ was recovered for utilization in functional studies. Therefore, we isolated RNA from the zebrafish hearts and prepared the Mb cNDA cDNA (genbank accession \#AY337025) and expressed (6g/2L of culture) the corresponding protein using the Novagen pET vector expression system as described in Materials and Methods.

Oxygen affinity and oxygen dissociation constants for each Mb protein were estimated in order to determine whether fish Mb proteins from species inhabiting different temperature regimes exhibit distinct functional characteristics. Oxygen affinities were determined by measuring the $\mathrm{O}_{2}$ equilibrium constants $\left(\mathrm{P}_{50}\right)$ at $25^{\circ} \mathrm{C}$. The results illustrated in Table 3 indicate no significant difference in oxygen affinity between myoglobins from zebrafish $(1.0 \mathrm{~mm} \mathrm{Hg}), N$. coriiceps $(0.6 \mathrm{~mm} \mathrm{Hg})$ and yellowfin tuna (1.0mm Hg). However, mackerel Mb exhibited a significantly lower affinity for oxygen $\left(\mathrm{P}_{50}=3.7 \mathrm{~mm} \mathrm{Hg}\right)$

$\mathrm{O}_{2}$ dissociation constants for $N$. coriiceps, zebrafish, yellowfin tuna, and mackerel were measured using a stopped-flow spectrophotometer (Figure 1). $\mathrm{O}_{2}$ dissociation from Mb was similar between $N$. coriiceps, zebrafish, and yellowfin tuna at all temperatures studied. However, $\mathrm{O}_{2}$ dissociation measured from mackerel Mb was approximately 2fold faster at all temperatures $\left(2-\right.$ to- $\left.20^{\circ} \mathrm{C}\right)$. These results indicate that $N$. coriiceps, 


\section{Oxygen dissociation rate constants}

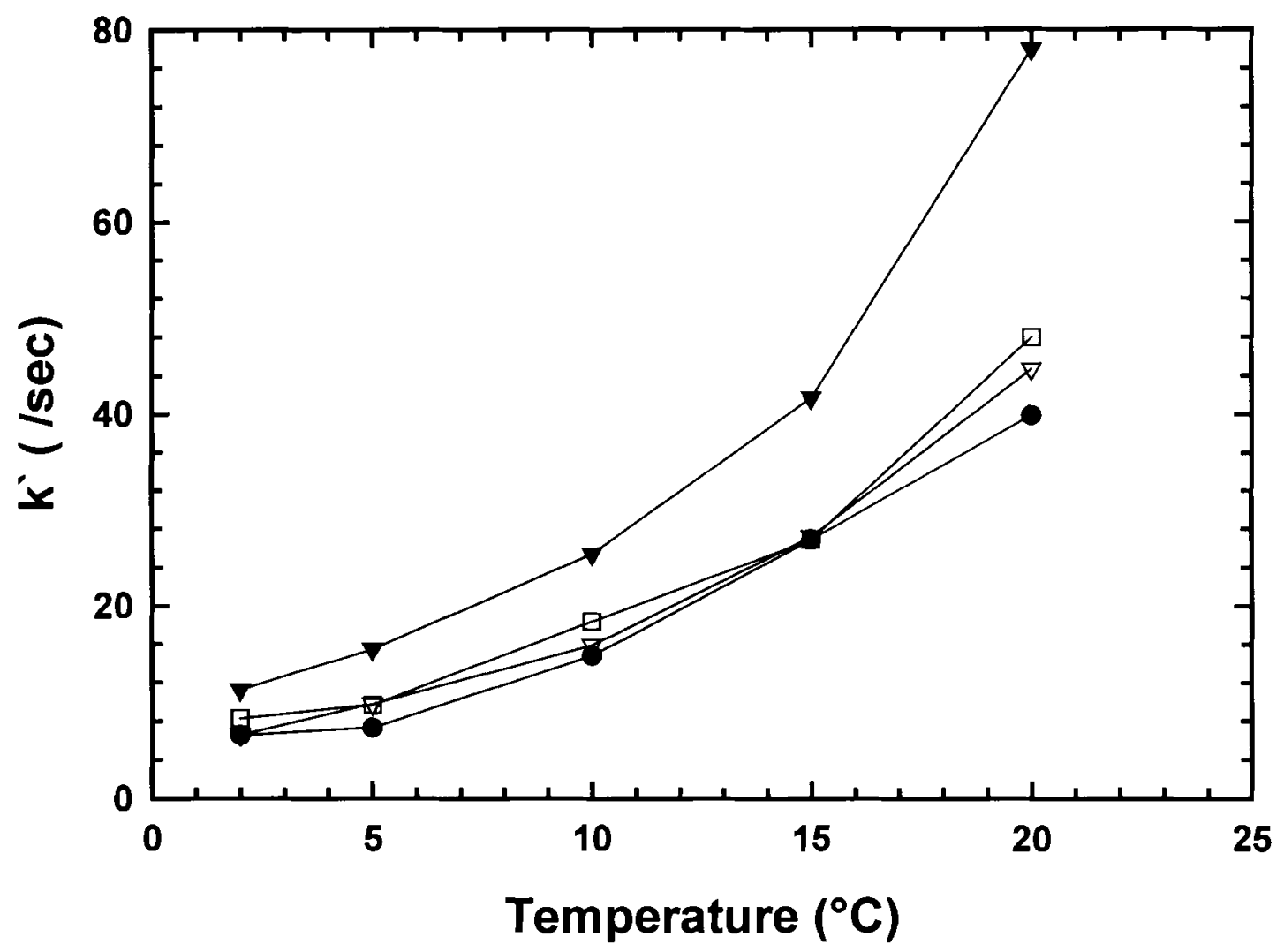

Figure 1. Oxygen dissociation rate constants. Dissociation rate constants $\left(\mathrm{k}^{\prime} / \mathrm{sec}\right)$ are plotted vs. temperature in degrees Celsius. $\bullet$, yellowfin tuna $\left(^{*}\right)$; $\boldsymbol{\nabla}$, mackerel; $\square$, zebrafish; $\nabla, N$. coriiceps. $\left({ }^{*}\right)$ Represents data from Cashon et al., 1997. 


\section{Oxygen equilibrium and Autooxidation}

\begin{tabular}{|c|c|c|c|}
\hline \multirow[b]{2}{*}{ Myoglobin } & \multirow{2}{*}{$\frac{\mathrm{P}_{50} \text { at } 25^{\circ}}{(\mathrm{mmHg})}$} & \multicolumn{2}{|c|}{ Autooxidation at $37^{\circ} \mathrm{C}$} \\
\hline & & $\overline{\text { Rate (hr-1) }}$ & $\mathbf{t}_{1 / 2}$ (hr) \\
\hline Yellowfin Tuna & 1.0 & 0.09 & 7.8 \\
\hline Zebrafish & 1.0 & 0.22 & 3.14 \\
\hline N. coriiceps & 0.6 & 0.44 & 1.57 \\
\hline Mackerel & 3.7 & 0.26 & 2.7 \\
\hline
\end{tabular}

Table 3. Mb oxygen equilibrium and autooxidation. Teleost myoglobin oxygen equilibrium constants $\left(\mathrm{P}_{50}\right)$ at $25^{\circ} \mathrm{C}$, and autooxidation rate constants and half life $\left(\mathrm{t}_{1 / 2}\right)$ at $37^{\circ} \mathrm{C}$. 
zebrafish, and yellowfin tuna $\mathrm{Mb}$ are functionally similar over a temperature range of 2 to- $20^{\circ} \mathrm{C}$, but mackerel $\mathrm{Mb}$ released oxygen more rapidly at all temperatures.

Arrhenius plots of the $\mathrm{O}_{2}$ dissociation data are shown in Figure 2. The slopes for each $\mathrm{Mb}$ were identical, indicating similar enthalpic energies of activation for the ligand dissociation. However, the y-intercept of the Arrhenius plot for mackerel Mb was significantly higher than that seen for all other species. This higher intercept value suggests differences between mackerel $\mathrm{Mb}$ and the other three teleost Mbs with respect to the entropy of activation associated with oxygen dissociation. Together, these results indicate that the ligand interactions of the Mbs of the stenothermic species ( $N$. coriiceps, zebrafish, and yellowfin tuna) are similar with respect to both oxygen affinity and oxygen dissociation, while the Mb from the eurythermal species (mackerel) differs with respect to both parameters. It is surprising that $N$. coriiceps and zebrafish Mb exhibit similar oxygen affinity and dissociation since the physiological temperatures, $-1.86^{\circ} \mathrm{C}$ and $27^{\circ} \mathrm{C}$ respectively, experienced by these teleost fish differ drastically.

Autooxidation rates of the ferrous forms of each $\mathrm{Mb}$ were determined at $37^{\circ} \mathrm{C}$ (Table 3 and Fig 3). These results show a positive correlation between the half-life of the ferrous state of the heme iron and the environmental temperatures experienced by the different species. The most stable $\mathrm{Mb}$ is the protein from yellowfin tuna (homethermic), followed by zebrafish (stenothermal tropical), mackerel (eurythermal), and $N$. coriiceps (stenothermal cold). The apparent relationship between autooxidation rate and environmental temperature is consistent with previous studies (Cashon et al, 1997). However, there was no spectral evidence for denaturation or unfolding of the $N$. coriiceps $\mathrm{Mb}$ protein over the time period of the autooxidation experiments (data not shown). 


\section{Arrhenius Plots of Off Rates}

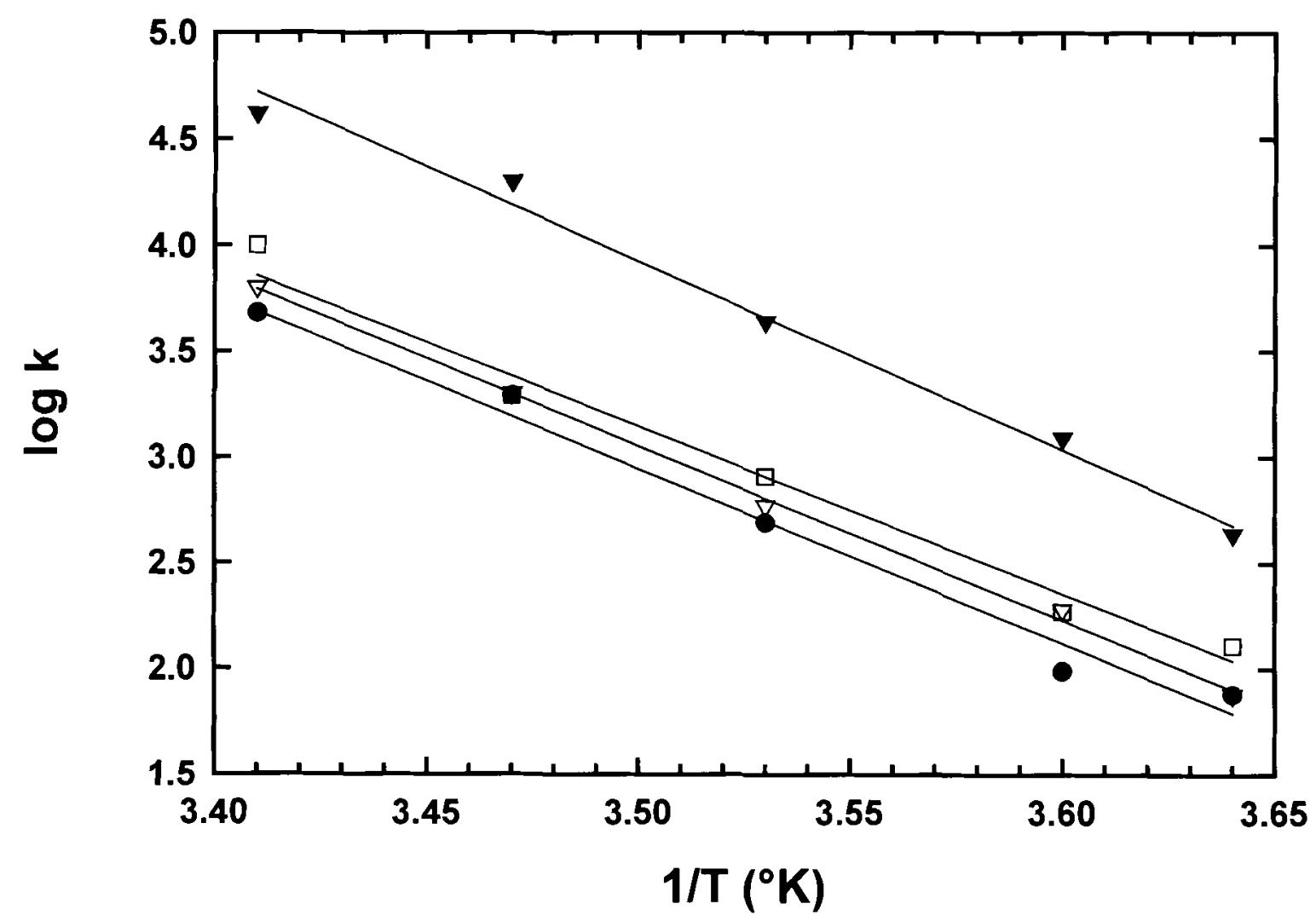

Figure 2. Arrhenius plots of oxygen dissociation rate constants. The natural $\log$ of oxygen dissociation rate constants are plotted vs. the inverse of temperature degrees Kelvin and multiplied by 1,000. Linear regressions were fit to each species. •, yellowfin tuna; $\nabla$, mackerel; $\square$, zebrafish; $\nabla, N$. coriiceps. 


\section{Autooxidation of myoglobins}

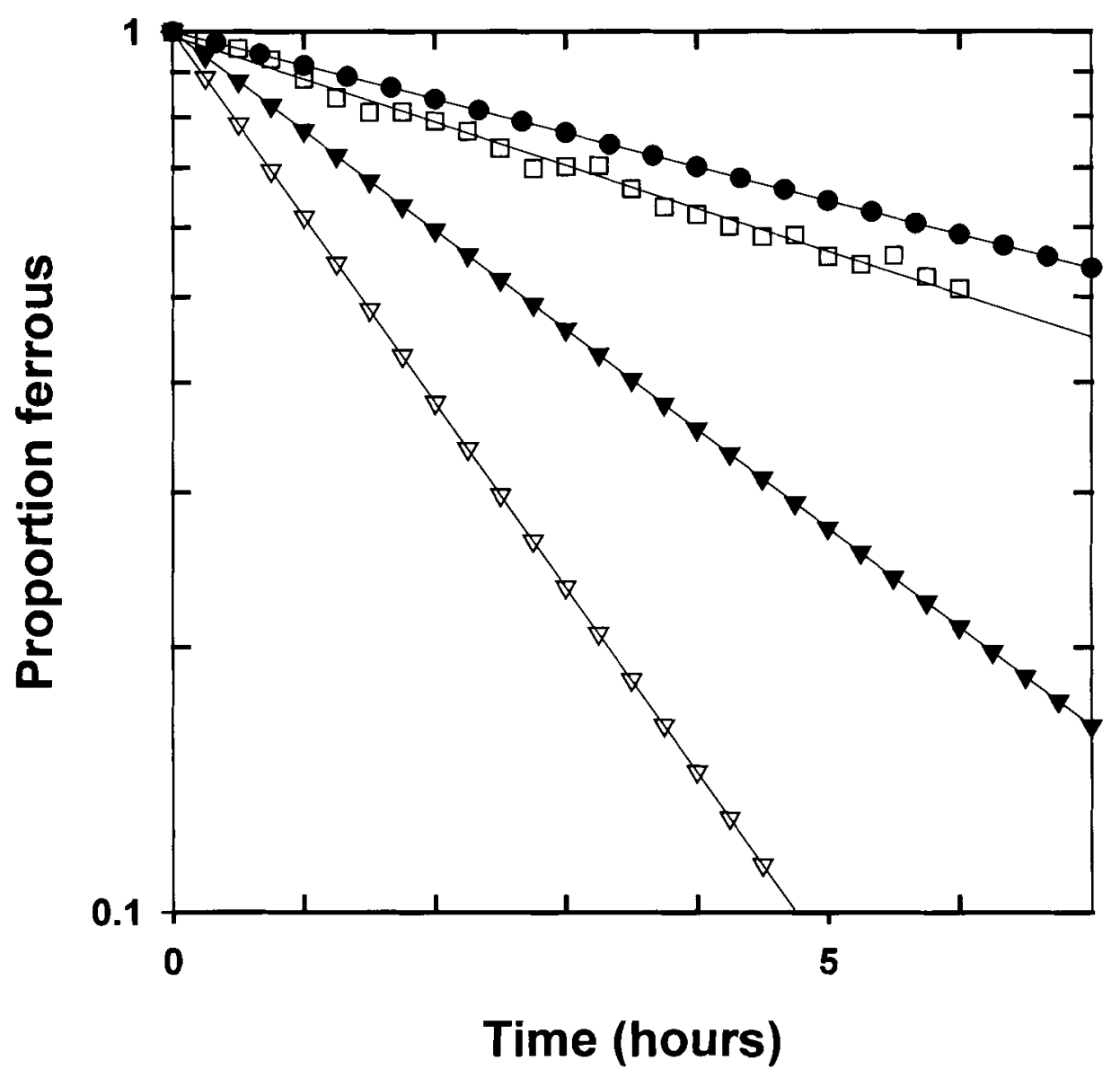

Figure 3. Autooxidation of myoglobins at $37^{\circ} \mathrm{C}$. The first order plots show the proportion of myoglobin remaining in the ferrous oxidation state as a function of incubation time at $37^{\circ} \mathrm{C}$. $\bullet$, yellowfin tuna*; $\nabla$, mackerel*; $\square$, zebrafish; $\nabla, N$. coriiceps. $\left({ }^{*}\right)$ Represents data from Cashon et al., 1997. 
When considered together with the ligand binding and equilibrium results presented above, these stability studies suggest that optimization of protein structure, in response to environmental temperature differences, can affect different functional characteristics of the protein in different ways and to different degrees. Thus, it was of interest to identify protein structural differences that might explain these functional differences.

\section{Structural Modeling of Mb Proteins}

The primary $\mathrm{Mb}$ sequence alignment for yellowfin tuna, $N$. coriiceps, mackerel, and zebrafish is shown in Figure 4. Yellowfin tuna $\mathrm{Mb}$ is $78 \%, 82 \%$, and $70 \%$ identical to the primary sequence of $N$. coriiceps, mackerel and zebrafish $\mathrm{Mb}$, respectively. The Mb polypeptide sequence of $N$. coriiceps $\mathrm{Mb}$ is $73 \%$ and $66 \%$ identical to mackerel and zebrafish $\mathrm{Mb}$ respectively, and mackerel $\mathrm{Mb}$ is $66 \%$ identical to the primary $\mathrm{Mb}$ sequence of zebrafish. These data indicate that teleost Mbs differ considerably from one another and that tuna $\mathrm{Mb}$ is not representative of all teleost $\mathrm{Mb}$. Figure 4 shows that residue differences are spread throughout the primary structure among these four $\mathrm{Mb}$ species, making it difficult to discern which, if any, of these specific residues contribute to functional variation among teleost Mbs.

RMS deviations of the positions of backbone C $\alpha$ carbons during the molecular dynamics simulations are shown in Figure 5. The filled symbols are for simulations at $0^{\circ} \mathrm{C}$ while open symbols represent data for simulations at $25^{\circ} \mathrm{C}$. All myoglobins show three major areas of apparent high flexibility of backbone structure: the D loop, and the 


\begin{tabular}{|c|c|c|c|c|c|c|}
\hline & \multicolumn{2}{|c|}{ A-helix } & , B-hellx & & CD bend & D-loop \\
\hline & 5 & 15 & 25 & 35 & 45 & $\begin{array}{l}55 \\
\end{array}$ \\
\hline spermwhale & VLSEGEWQLV & LHVWAKVEAD & VAGHGQDILI & RLFKSHPETL & EKFDRFKHLK & TEAEMKASED \\
\hline yellowfin & $---A D F D A V$ & LKCWGPVEAD & YTTMGGLVLT & RLFKEHPETQ & KLFPKFAGI- & AQADIAGNAA \\
\hline mackerel & $---A D F D A V$ & LKFWGPVEAD & YTNIGNMVLT & RLFAEHPDTQ & KLFPKFAGI- & GQGDMAGNAA \\
\hline N. coriiceps & $----\mathrm{ADFDMV}$ & LKCWGPMEAD & YATHGGLVLT & RLFTEHPETL & KLFPKFAGI- & AHGDLAGDAG \\
\hline zebrafish & ---- ADHDLV & LKCWGAVEAD & YAANGGEVLN & RLFKEYPDTL & KLFPKFSGI- & SQGDLAGSPA \\
\hline & Eh & & F- & elix & & \\
\hline & 65 & 75 & 85 & 95 & 105 & 115 \\
\hline spermwhale & LKKHGVTVLT & ALGAILKKKG & HHEAELKPLA & QSHATKHKIP & IKYLEFISEA & I IHVLHSRHP \\
\hline yellowfin & ISAHGATVLK & KLGELLKAKG & SHAAI LKPLA & NSHATKHKIP & INNFKLISEV & LVKVMHEKAG \\
\hline mackerel & ISAHGATVLK & KLGEVLKAKG & NHASIVKPLA & NSHATKHKIA & INNFKLITEI & IVKVMQIKAG \\
\hline N. coriiceps & VSAHGATVLN & KLGDLLKARG & AHAALLKPLS & SSHATKHKIP & I INFKLIAEV & IGKVMEEKAG \\
\hline ebrafish & VAAHGATVLK & GELLKAKG & AALLKPLA & NTHANIHKVA & LNNFRLITEV & LVKVMAEKAG \\
\hline
\end{tabular}

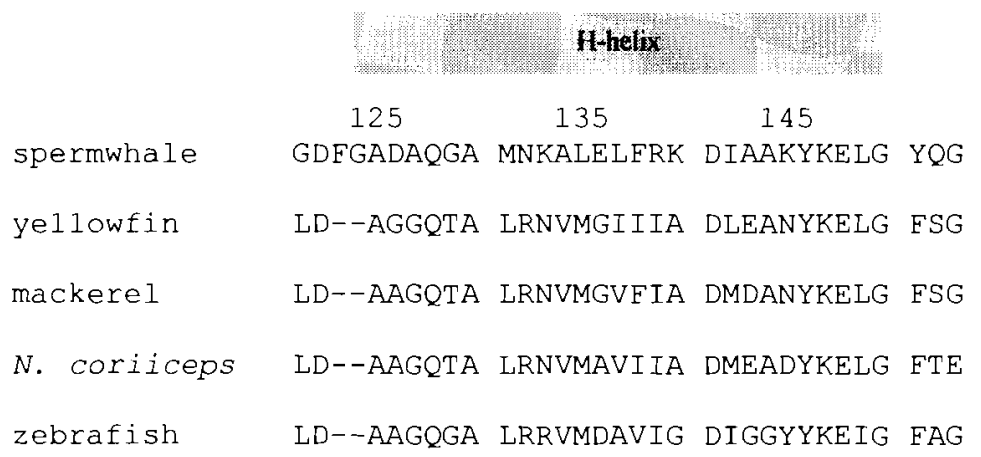

Figure 4. Primary sequence alignment of teleost fish myoglobin. The primary sequence of yellowfin tuna, $N$. coriiceps, mackerel, and zebrafish is shown above. The seven $\alpha$-helices, D-loop, and CD-bend are shown as shaded bars above the sites making up these secondary structures. Residues conserved to the yellowfin tuna myoglobin are represented by $(\bullet)$. Heme binding residues His (E7) and His (F8) are depicted by $\left(^{*}\right)$. Residues 152 and 153 of Mackerel are based on the teleost Mb consensus sequence and also reported by Marcinek et al (2001). 


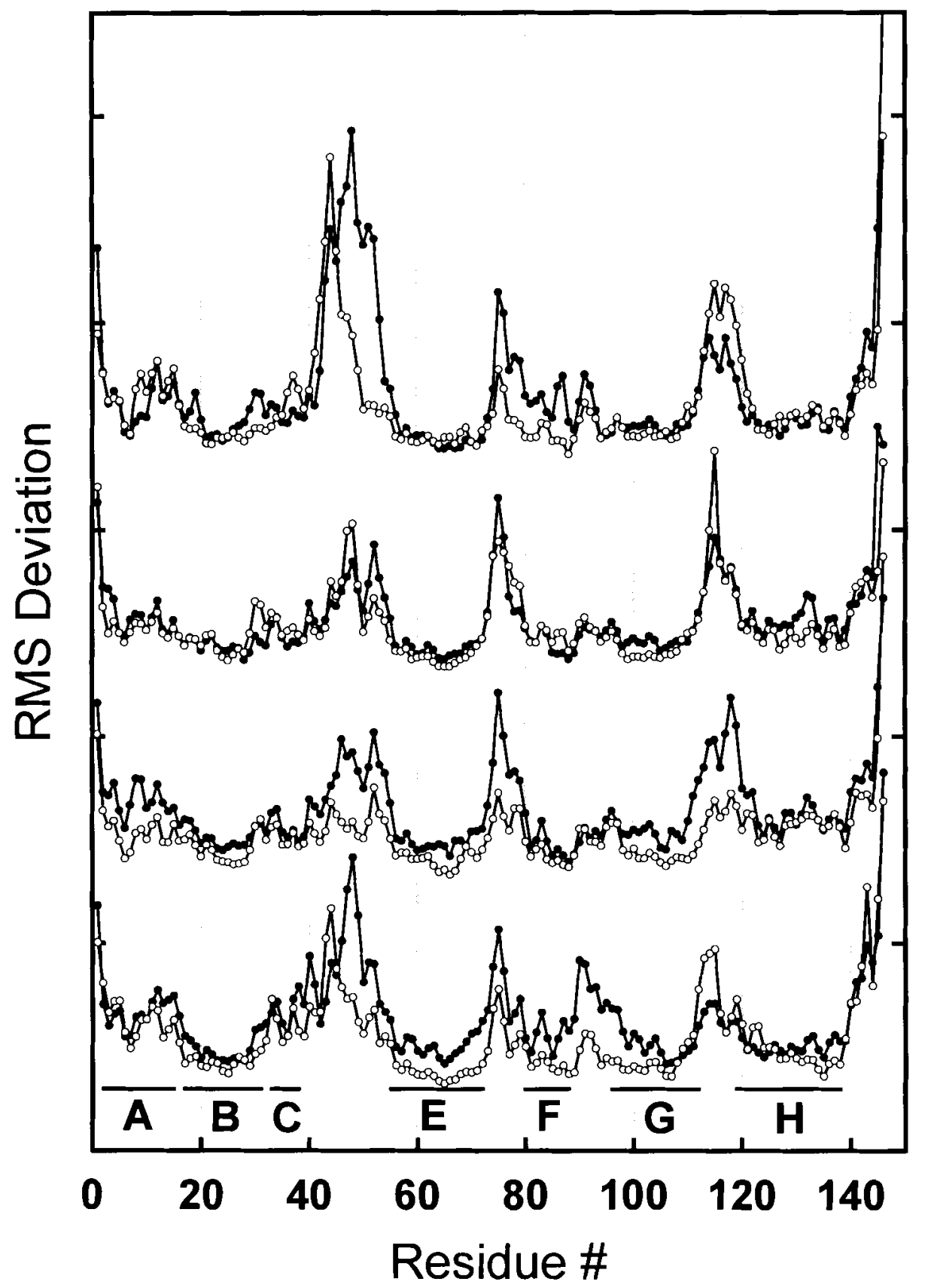

Figure 5. RMS deviations of the positions of backbone $\mathbf{C} \alpha$ carbons during the molecular dynamics simulations. $\bullet 298$ degrees Kelvin and $\circ 273$ degrees Kelvin (over 200 ps time window). From bottom to top simulations represent myoglobins from yellowfin tuna, $N$. coriiceps, zebrafish, and mackerel. The RMS fluctuations of each species is offset by $1 \AA$ (bottom to top) for clarity of presentation 
regions of the $\mathrm{EF}$ and $\mathrm{GH}$ turns between helices. The proteins from tuna and mackerel also show an apparent increased flexibility in the region between helixes $F$ and $G$ (FG turn) although this is not as pronounced as in the other regions noted. Overall, the $\mathrm{Mb}$ from mackerel shows the highest degree of apparent flexibility at both temperatures. This is particularly apparent in the D loop region which shows a high degree of movement at both temperatures, but with differences in the specific residues which contribute to the flexibility at the two temperatures. As with mackerel, both tuna and $N$. coriiceps Mbs show higher flexibility in the D loop region at the higher temperature, but the difference is not as apparent as seen with mackerel Mb. In general, the simulations of zebrafish $\mathrm{Mb}$ show little apparent effect of temperature on backbone flexibility although the overall pattern of RMS movement in zebrafish Mb is very similar to $N$. coriiceps $\mathrm{Mb}$. 


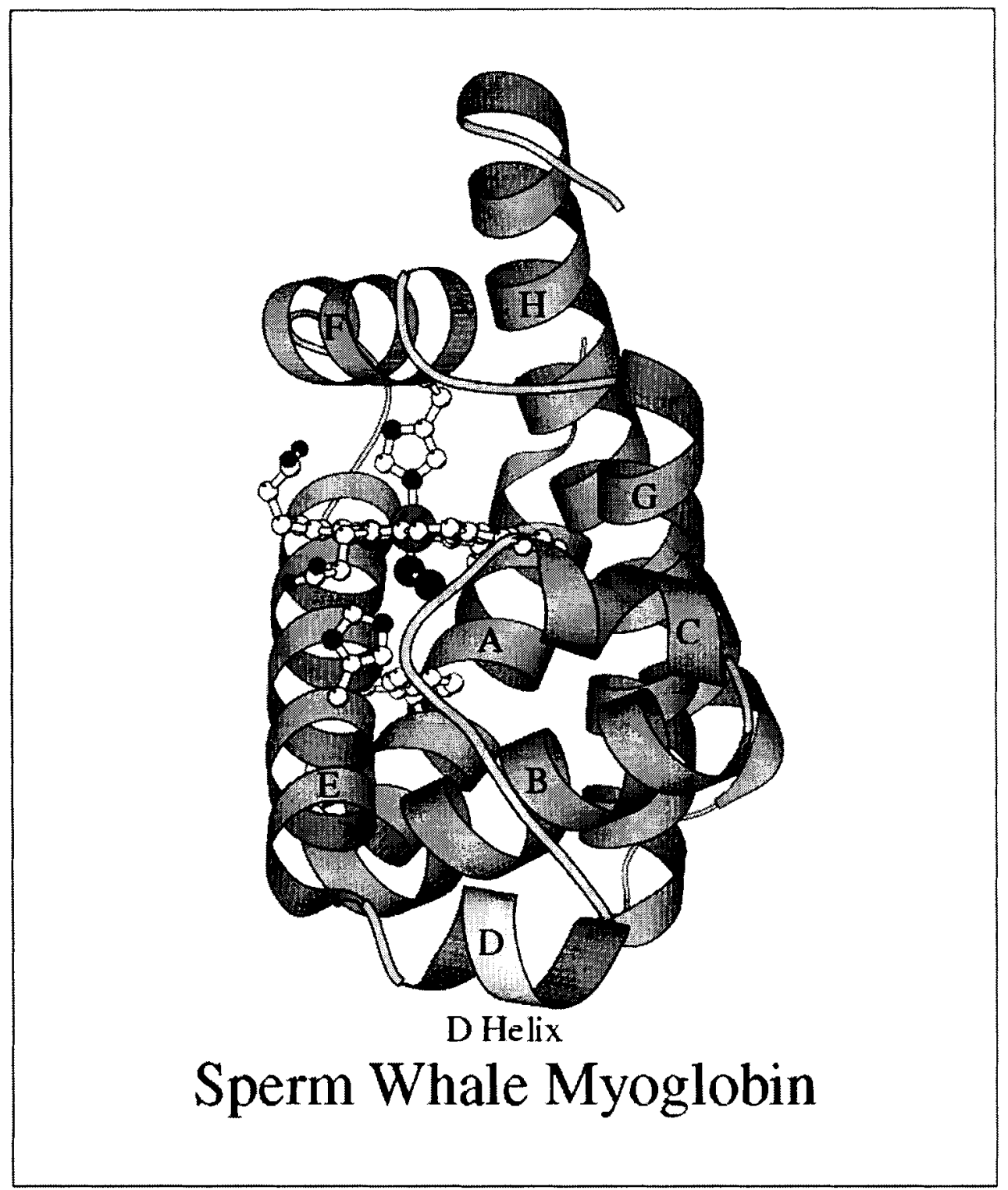

Figure 6. Ribbon structure of sperm whale myoglobin. 


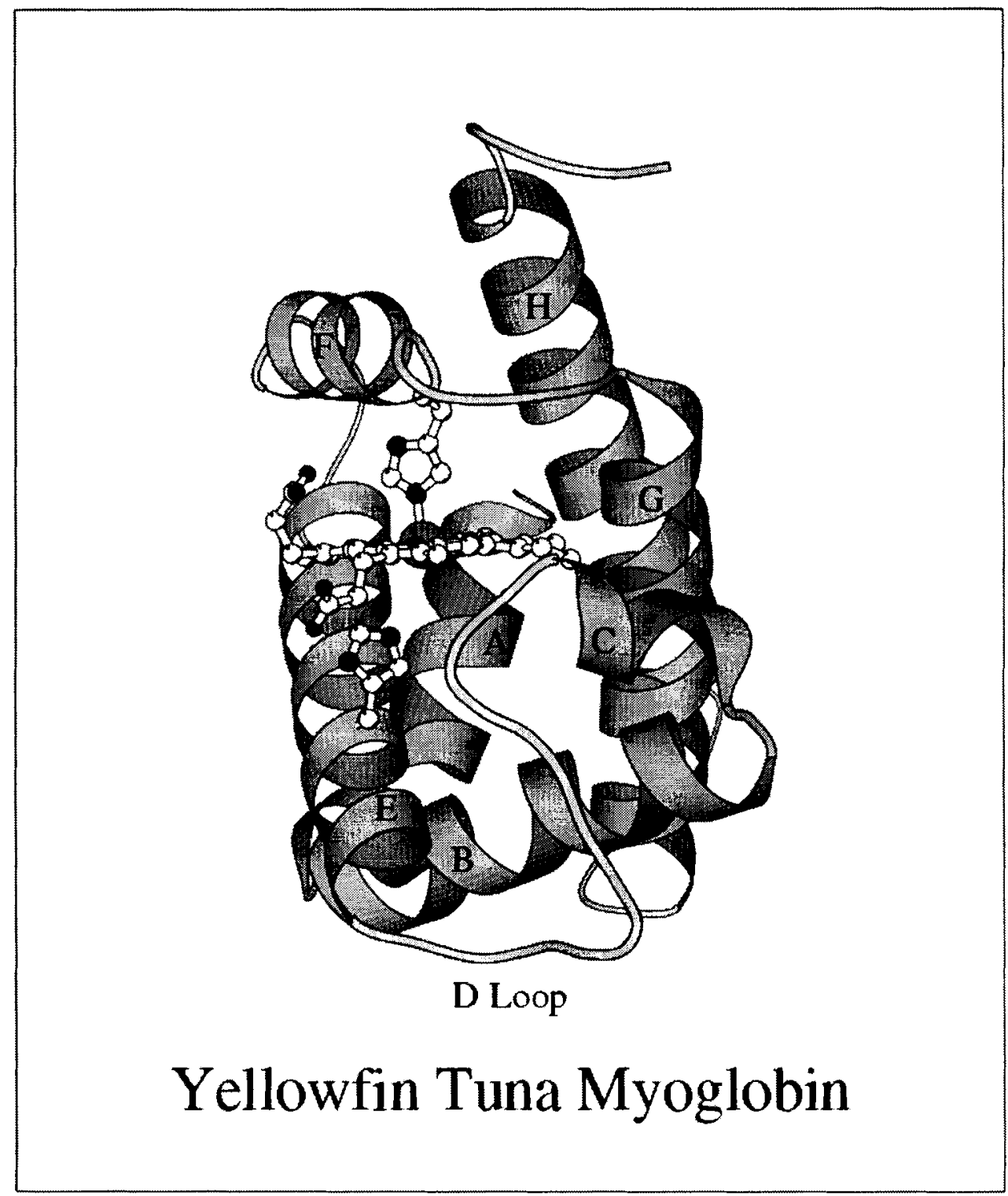

Figure 7. Ribbon structure of yellowfin tuna myoglobin. 


\section{DISCUSSION}

To date, tuna $\mathrm{Mb}$ is the best studied teleost $\mathrm{Mb}$ and its crystal structure has been determined (Birnbaum et al., 1994). However, our study indicates that tuna is not representative of all teleost myoglobins. The teleost polypeptide sequences exhibit a wide range of sequence divergence, with generally only $70 \%$ identity to one another (Fig 4). This result is in contrast to mammalian Mbs that show non-conservative substitutions at only 7 residues, and avian and reptilian myoglobin proteins which display greater than $85 \%$ sequence identity to one another (Blanchetot et al., 1983, Weller et al., 1984, Akaboshi 1985; Blanchetot et al., 1986). Further, mammalian Mb is highly conserved in both structure and function, where $\mathrm{O}_{2}$ binding and dissociation properties are virtually identical between horse and sperm whale. (Antonini et al., 1971 and Cashon et al., 1997). In terms of kinetic characteristics, our study demonstrates that at least one teleost $\mathrm{Mb}$, mackerel, exhibits significantly different $\mathrm{P}_{50}$ and oxygen dissociation rates. The autooxidation rates of zebrafish $\mathrm{Mb}$ and $N$. coriiceps $\mathrm{Mb}$ are also significantly different, indicating differing functional stability between the proteins. Finally, our molecular dynamic modeling also shows that the four Mbs studied exhibit different predicted patterns of flexibility and molecular motion. We conclude that teleost Mbs show overall different characteristics, which we hypothesize can be attributed to the fact that teleost Mbs function in different temperature regimes and are not subjected to a constant $37^{\circ} \mathrm{C}$ as is the case with mammalian $\mathrm{Mb}$.

However, it is intriguing that kinetic properties of teleost Mb do not correlate with the temperature at which the myoglobin functions. Yellowfin tuna, zebrafish, and $N$. 
coriiceps Mbs exhibit essentially identical kinetic parameters even though they function at $30^{\circ} \mathrm{C}, 27^{\circ} \mathrm{C}$, and $-1.86^{\circ} \mathrm{C}$, respectively. The outlier of this study is the mackerel $\mathrm{Mb}$, which is a eurythermal species that experiences different thermal environments on a daily and seasonal basis. By contrast, tuna is a homeotherm and zebrafish and $N$. coriiceps are stenothermal, experiencing little temperature variation, a similar situation to mammals. Each species are listed in Table 1 along with their appropriate physiological temperature regime and corresponding tolerance classification.

Zebrafish and $N$. coriiceps $\mathrm{Mb}$ show similar $\mathrm{P}_{50}$ values and almost identical oxygen dissociation rates. However, data reveal that zebrafish and $N$. coriiceps $\mathrm{Mb}$ are distinct from one another. Both Mbs show similar flexibility patterns in their RMS plots, however, zebrafish $\mathrm{Mb}$ shows little difference in flexibility between the two temperatures measured, where $N$. coriiceps $\mathrm{Mb}$ shows higher variation in flexibility at $0^{\circ} \mathrm{C}$ and $25^{\circ} \mathrm{C}$, especially in the D-loop, EF, and GH motifs. There were also major differences in the autooxidation rates between the $\mathrm{Mb}$ of these two species. $N$. coriiceps is more labile $\left(t_{1 / 2}=1.57 \mathrm{~h}\right)$ versus zebrafish $\left(\mathrm{t}_{1 / 2}=3.14 \mathrm{~h}\right)$, which is predictable for proteins optimized to function at cold and warm temperature. Consistent with this conclusion, $N$. coriiceps $\mathrm{Mb}$ could be expressed in E. coli at $20^{\circ} \mathrm{C}$ but not at $37^{\circ} \mathrm{C}$ (data not shown), consistent with the lack of structural stability of this protein at high temperature.

It is very interesting to note that zebrafish and $N$. coriiceps $\mathrm{Mb}$ have almost identical oxygen binding kinetics, but very different autooxidation rates. These results suggest that there are different sites for entry of water and oxygen molecules into the protein. Autooxidation occurs by the accessibility of the heme group to solvent water molecules and oxygen binding occurs by the accessibility to oxygen (Brantley et al., 
1993). An early prediction, based on the structure of human hemoglobin (Perutz and Matthews, 1966) was that ligand entry is through the short pathway normally or partially occupied by the distal histidine, H64(E7). Extensive kinetic studies of a large number of mutations to sperm whale myoglobin strongly suggest that in this mammalian protein, the major pathway for ligand movement is through this portal controlled by the distal histidine (Scott et al, 2001). Substitution of smaller groups for the imidazole side chain of the distal histidine enhances oxygen recombination rates while substitution of the larger tryptophan residue slows the movement of oxygen into the pocket. The pathway for entry and exit of oxygen into mammalian Mbs (if such a unique pathway exists) remains a point of discussion. Other investigators have utilized molecular dynamics studies or kinetic studies of random $\mathrm{Mb}$ mutants to argue that the protein lacks a discrete channel for oxygen binding and release. In these models, oxygen migrates into the globin structure through pathways opened by random movements in the structure, facilitated by flexibility of the protein structure (Lambright et al., 1994; Huang and Boxer, 1994). This mode of ligand movement might further incorporate secondary cavities (the so-called Xenon cavities) in the globin structure which facilitate oxygen diffusion (Brunori et al., 1999; Draghi et al, 2002). These considerations support the possibility that the specific mode of ligand entry and escape might vary between different oxygen binding proteins or between related variants of the same protein. In light of the general structural and functional differences between mammalian and teleost myoglobins there is no compelling reason to believe that the routes of oxygen movements are the same in the two groups of proteins. The teleost myoglobin structure is considered to be more flexible as judged by the lack of D-helix and evidence based on molecular dynamics simulations of the teleost 
proteins. These differences could possibly enhance oxygen movement through the globin structure and explain both the variation seen in ligand interactions within the teleost $\mathrm{Mb}$ group and the general differences seen between mammalian and teleost myoglobins.

Mackerel Mb as shown in this study and others, exhibits major differences in oxygen dissociation rates, $\mathrm{P}_{50}$ values, and predicted structural flexibility in comparison with the other teleost Mbs (Marcinek et al., 2001; Cashon et al, 1997). We feel this difference might be due to the possible structural difference in the D-helix region. Comparison of the teleost myoglobin sequences that we have determined reveals that the residue corresponding to helix position D5 is either methionine ( 3 cases, as in mammals), leucine (remainder of $\mathrm{Mbs}$, as in the turtle $\mathrm{Mb}$ ), or isoleucine that is only reported in yellowfin tuna. It has been shown that a methionine at the D5 position $\left(\mathrm{Met}^{55}\right)$ is critical in the formation of a $\mathrm{D}$ helix in sperm whale $\mathrm{Mb}$ (Whitaker et al., 1995). Substitution of alanines for the remaining D-helix residues do not cause unfolding of the helix and loop formation as long as $\mathrm{Met}^{55}$ is present, suggesting a very important role for the methionine residue at the $\mathrm{D} 5$ position. This opens the possibility that some teleost Mbs might have a D-helix in place of the D-loop, and therefore the tuna protein, which have been used as the basis for our homology models of other teleost Mbs, would not provide a representative teleost $\mathrm{Mb}$ structure. The other possibility is that the absence of the $\mathrm{D}$ helix in teleost Mbs, based on the yellowfin tuna backbone, is due to structural factors other than the methionine residue critical in the sperm whale D-helix structure. Our RMS plot of mackerel myoglobin structure $\left(\mathrm{Met}^{55}\right.$ is present in mackerel $\mathrm{Mb}$ ) show that there is significantly more predicted flexibility in the region of the D-helix/loop. We have also homology modeled mackerel $\mathrm{Mb}$ from the horse $\mathrm{Mb}$ sequence and this model predicts 
much less flexibility in D-helix/loop region, suggesting that a D-helix may form in mackerel $\mathrm{Mb}$ (data not shown). Atlantic salmon, rainbow trout, and marlin all exhibit a methionine at the D5 position (data not shown). These species also experience different thermal regimes during their life cycle, and therefore it will be interesting to determine whether oxygen kinetics of these myoglobin proteins is similar to that of mackerel.

Future studies are aimed at determining whether specific changes in teleost myoglobin structure affect changes in ligand-binding and dissociation kinetics, thermal stability, and oxidative stability. We will address this question by examining the stability and ligand binding interactions of natural teleost myoglobins and site-directed mutants of these proteins. The regions of interest will focus on three areas of the protein known to vary among teleost species: the D-loop region, the oxygen-binding pocket, and connecting loop regions between helices predicted by molecular dynamic modeling to affect flexibility of the protein.

Previous sequence analysis has determined that amberjack and marlin Mb possess a methionine residue at the $\mathrm{D} 5$ position. It will be interesting to determine whether these Mbs also produce similar oxygen affinity and dissociation kinetics to that of mackerel $\mathrm{Mb}$, which also has a methionine at the D5 position. A comparison will also be made with teleost myoglobins which have leucine (zebrafish, $N$. coriiceps) or isoleucine (yellowfin tuna) at the D5 position. We will perform molecular modeling of these structures using homology models based on tuna and horse myoglobin as templates to predict whether observed sequence differences might predict formation of a stable Dhelix in these teleost myoglobins and thus alter flexibility of the region. This study will tell us if the unique functional properties seen in mackerel myoglobin are mirrored in 
other teleost myoglobins with methionine at helix position D5 as would be predicted based on mammalian myoglobin structure/function studies.

The final objective of this project will be to express site-directed mutants that have been changed at the D5 position of the helix/loop region, and determine whether this has affected each Mbs oxygen affinity and oxygen dissociation kinetics. We will express tuna, mackerel, zebrafish and $N$. coriiceps myoglobins in $E$. coli. Site-directed mutants will be prepared that will place methionine, leucine, and isoleucine at the D5 position in the context of the tuna, mackerel, zebrafish and $N$. coriiceps structures, respectively. Kinetics, autooxidation and thermal stability of the expressed variant proteins will then be measured. It is anticipated that this study will determine whether the identity of the D5 amino acid is critical to D-helix formation, and will determine whether flexibility in the D-loop affects ligand-binding kinetics and stability of the proteins. 


\section{REFERENCES}

Akaboshi, E., 1985. Cloning and sequence analysis of porcine myoglobin cDNA. Gene. 40, 137-140.

Antonini, E., Brunori, M., 1971. Hemoglobin and myoglobin in their interactions with ligands. Elsevier Science Publishing Co., Inc., New York, NY.

Birnbaum, G.I., Evans, S.V., Przybylska, M., Rose, D.R., 1994. 1.70 A resolution structure of myoglobin from yellowfin tuna. An example of a myoglobin lacking the D helix. Acta Cryst. D50, 283-289.

Blanchetot, A., Wilson, V., Wood, D., Jeffreys, A.J., 1983. The seal myoglobin gene: an unusually long globin gene. Nature. 301, 732-734.

Blanchetot, A., Price, M., Jeffreys, A.J., 1986. The mouse myoglobin gene. Characterization and sequence comparison with other mammalian myoglobin genes. Eur. J. Biochem. 159(3), 469-474.

Brantley, R.E., Smerdon, S.J., Wilkinson, A.J., Singleton, E.W., Olson, J.S., 1993. The mechanism of autooxidation of myoglobin. J. Biol. Chem. 268(10), 6995-7010.

Brooks, B.R., Bruccoleri, R.E., Olafson, B.D., States, D.J., Swaminathan, S., Karplus, M., 1983. CHARMM: A program for macromolecular energy, minimization, and dynamics calculations. J. Comp. Chem. 4, 187-217.

Brunori, M., Cutruzzola, F., Savino, C., Travaglini-Allocatelli, C., Vallone, B., Gibson, Q.H., 1999. Structural dynamics of ligand diffusion in the protein matrix: A study on a new myoglobin mutant Y(B10) Q(E7) R(E10). Biophys. J. 76, 1259-1269.

Cashon, R.E., Alayash, A.I., 1995. Reaction of human hemoglobin $\mathrm{HbA}_{0}$ and two crosslinked derivatives with hydrogen peroxide: Differential behavior of the ferryl intermediate. Arch. Biochem. Biophys. 316, 461-469.

Cashon, R.E., Vayda, M.V., Sidell, B.D., 1997. Kinetic characterization of myoglobins from vertebrates with vastly different body temperatures. Comp. Biochem. Physiol. $17 \mathrm{~B}(4), 613-620$.

Draghi, F., Miele, A.E., Travaglini-Allocatelli, C., Vallone, B., Brunori, M., Gibson, Q.H., Olson, J.S., 2002. Controlling ligand binding in myoglobin by mutagenesis. J. Biol. Chem. 277(9), 7509-7519.

Fields, P., Somero, G.N., 1997. Amino acid sequence differences cannot fully explain interspecific variation in thermal sensitivities of gobiid fish A4-lactate dehydrogenases (A4-LDHs). J. Exp. Biol. 200, 1839-1850. 
Garry, D.J., Ordway, G.A., Lorenz, J.N., Radford, N.B., Chin, E.R., Grange, R.W., Bassel-Duby, R., Williams, R.S., 1998. Mice without myoglobin. Nature. 395, 905-908.

Hegesh, E., Avron, M., 1967. The enzymatic reduction of ferrihemoglobin. I. The reduction of ferrihemoglobin in red blood cells and hemolysates. Biochem. Biophys. Acta. 146, 91-101.

Henikoff, J.G., Henikoff, S., Pietrokovski, S., 1999. Nucleic Acids Research 27(1), 226-228.

Higgins, D.G., Sharp, P.M., 1988. CLUSTAL: a package for performing multiple sequence alignment on a microcomputer. Gene. 73, 237-244.

Higgins, D.G., 1994. CLUSTAL V: multiple alignment of DNA and protein sequences. Methods Mol. Biol. 25, 307-318.

Hochachka, P.W., Somero, G.N., 2002. Biochemical adaptation: Mechanism and process in physiological evolution. Oxford Press, New York, NY.

Huang, X., Boxer, S.G., 1994. Discovery of new ligand binding pathways in myoglobin by random mutagenesis. Nat. Struct. Biol. 1, 226-229.

Lambright, D.G., Balasubramanian, S., Decatur, S.M., Boxer, S.G., 1994. Anatomy and dynamics of ligand-binding pathway in myoglobin: The roles of residues 45, 60, and 68 . Biochemistry. 33, 5518-5525.

Lattman, E.E., Nockolds, C.E., Kretsinger, R.H., Love, W.E., 1971. Structure of yellowfin tuna myoglobin at $6 \AA \AA$. J. of Mol. Biol. 60, 271-277.

Livingston, D.J., Brown, D.W., 1981. The chemistry of myoglobin and its reactions. Food Technology. 244-252.

Marcinek, D.J., Bonaventura, J., Wittenberg, J.B., Block, B.A., 2001. Oxygen affinity and amino acid sequence of myoglobins from endothermic and ectothermic fish. Am. J. Physiol. Reg. Int. Comp. Physiol. 280, 1123-1133.

Nardini, M., Tarricone, C., Rizzi, M., Lania, A., Desideri, A., De Sanctis, G., Coletta, M., Petruzzelli, R., Ascenzi, P., Coda, A., Bolognesi, M., 1995. Reptile heme protein structure: X-ray crystallographic study of the aquo-met and cyano-met derivatives of the loggerhead sea turtle Caretta caretta myoglobin at 2.0 angstrom resolution. J. Mol. Biol. $247,459-465$.

Nichols, J.W., Weber, L.J., 1989. Comparative oxygen affinity of fish and mammalian myoglobins. J. Comp. Biochem. 159B, 205-209. 
O'Brien, K.M., Sidell, B.D., 2000. The interplay among cardiac ultrastructure, metabolism and expression of oxygen-binding proteins in Antarctic fishes. J. Exp. Biol. 203, 1287-1297.

Perutz, M.F., Kendrew, J.C., Watson, H.C., 1965. Structure and function of haemoglobin II. Some relations between polypeptide chain configuration and amino acid sequence. J. Mol. Biol. 13, 669-678.

Perutz, M.F., Matthews, F.S., 1966. An x-ray study of azide methaemoglobin. J. Mol. Biol. 21(1), 199-202.

Phillips, S.E.V., 1980. Structure and refinement of oxymyoglobin at 1.6 A resolution. J. Mol. Biol. 142, 531-554.

Riggs, A., Wolbach, R.A., 1956. Sulphydryl groups and the structure of hemoglobin. J. Gen. Physiol. 39, 585-605.

Rose, T. M., Schultz, E. R., Henikoff, J. G., Pietrokovski, S., McCallum, C. M., Henikoff, S., 1998. Nucleic Acids research 26(7), 1628-1635.

Scott, E.E., Gibson, Q.H., Olson, J.S., 2001. Mapping the pathways for $\mathrm{O}_{2}$ entry into and exit from myoglobin. J. Biol. Chem. 276(7), 5177-5188.

Sidell, B.D., Vayda, M.E., Small, D.J., Moylan, T.J., Londraville, R.L., Yan, M., Rodnick, K.J., Eppley, Z.A., Costello, L., 1997. Variable expresson of myoglobin among the hemoglobinless Antarctic icefishes. Proc. Natl. Acad. Sci. 94, 3420-3424.

Stevens E.D., Carey, F.G., 1981. One why of the warmth of warm-bodied fish. Am. J. Physiol. 240(3), R151-155.

Takano, T., 1977. Structure of myoglobin refined at 2-0 A resolution. II. Structure of deoxymyoglobin from sperm whale. J. Mol. Biol. 110(3), 569-584.

Watts, D.A., Rice, R.H., Brown, W.B., 1980. The primary structure of myoglobin from yellowfin tuna (Thunnus albacares). J. Biol. Chem. 255(22), 10916-10924.

Weller, P., Jeffreys, A.J., Wilson, V., Blanchetot, A., 1984. Organization of the human myoglobin gene. EMBO J. 3, 439-446.

Whitaker, T.L., Berry, M.B., Ho, E.L., Hargrove, M.S., Philips, G.N., Komiyama, N.H., Nagai, K., Olson, J.S., 1995. The D-Helix in myoglobin and in the $\beta$ subunit of hemoglobin is required for the reduction of heme. Biochemistry $34,8221-8226$.

Wittenberg, J.B., Wittenberg, B.A., 1989. Transport of oxygen in muscle. Annu. Rev. Physiol. 51, 857-878. 
Vayda, M.E., Small, D.J., Yuan, M., Costello, L., Sidell, B.D., 1997. Conservation of the myoglobin gene among Antarctic notothenioid fishes. Mol. Mar. Biol. Biotechnol. 6, 207-216.

Voet, D., Voet, J.G., Pratt, C.W., 2002. Fundamentals of Biochemistry. John Wiley \& Sons, Inc., New York, NY. 


\section{BIOGRAPHY OF THE AUTHOR}

Peter William Madden was born in Millinocket, Maine on June 30, 1979. He was raised in Millinocket and graduated from Stearns High School in 1997. He attended the University of Maine and graduated in 2001 with a Bachelor of Science degree in Biochemistry. Peter stayed in Orono and entered the Biochemistry graduate program with the hope of attaining a Master's degree in the fall of 2001, concentrating on fish myoglobin with Dr. Robert Cashon.

After receiving his degree, Peter will be starting in the Business School's Master of Business Administration program at the University of Maine. Peter is a candidate for the Master of Science degree in Biochemistry from The University of Maine in December, 2003. 